\section{II Международный} библиографический конгресс

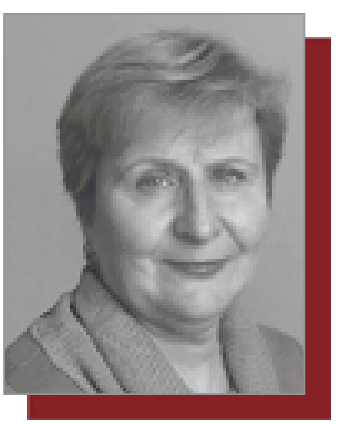

Александра Валентиновна

Теплицкая, заведуюшая Научноисследовательским отделол библиографии

Российской государственной библиотеки, кандидат педагогических наук, дочент

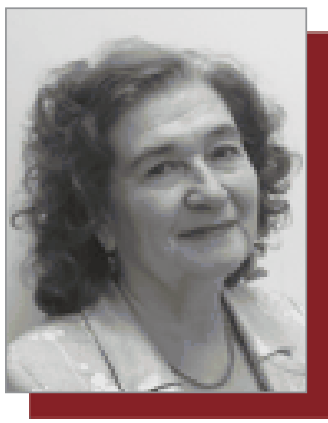

Людмила Васильевна Жукова, главный библиограф Научноисследовательского отдела библиографии

Российской государственной библиотеки

\section{Библиографи- ческие ресурсы национальных библиотек - членов Библио- течной Ассамблеи Евразии}

Представлен анализ библиографической продукиии, изданной (в печатнол и электроннол виде) национальныли библиотекали - членами Библиотечной Ассалблеи Евразии в 20102014 г2., дается сравнение нынешнего периода с предыдущил - 2004-2009 гг., вылвлены тендениии развития.

Ключевые слова: библиографические ресурсы, национальные библиотеки, Библиотечная Ассалблея Евразии.

( сновной задачей библиотек является формирование фондов и обслуживание читателей. Ориентироваться в огромном библиотечном мире возможно только используя библиографические ресурсы, которые в настоящее время реализуются в трех форматах: карточном, печатном, электронном. Если карточная библиографическая информация доступна ограниченному количеству читателей, то печатная и электронная ориентированы на аудиторию, находящуюся далеко за пределами библиотек. Проанализировать деятельность библиотек по продвижению библиографической информации до пользователей возможно только располагая сведениями о создаваемых библиотеками библиографических ресурсах. Именно таким источником информации является библиографический указатель «Издания и электронные ресурсы национальных библиотек государств - участников Содружества Независимых Государств, 2004-2014 гг.», который существует только в электронном виде уже более 10 лет (http://www.rsl.ru/datadocs/doc_4216wi. pdf). Указатель отражает многогранную издательскую деятельность национальных библиотек, в том числе и по раскрытию своих фондов и доведению до читателей знаний, хранящихся в этих фондах, библиографическими средствами. Перво- 
начально указатель отражал деятельность 12 библиотек, с 2010 г. 14: Азербайджанская национальная библиотека им. М.Ф. Ахундова, Национальная академическая библиотека Республики Казахстан, Национальная библиотека Армении, Национальная библиотека Беларуси, Национальная библиотека Кыргызской Республики, Национальная библиотека Республики Казахстан, Национальная библиотека Республики Молдова, Национальная библиотека Республики Таджикистан им. Абулькасима Фирдавси, Национальная библиотека Узбекистана им. Алишера Навои, Национальная библиотека Украины им. В.И. Вернадского, Национальная парламентская библиотека Украины, Президентская библиотека им. Б.Н. Ельцина, Российская государственная библиотека, Российская национальная библиотека. По ряду обстоятельств деятельность некоторых библиотек отражена неполно ${ }^{1}$. В указатель включены печатные издания и электронные публикации (в том числе и базы данных, если к ним есть доступ через Интернет), подготовленные национальными библиотеками: непериодические, сериальные (периодические и продолжающиеся) издания (за исключением публикаций в журналах, сборниках и т. д.) независимо от их целевого назначения. Электронные ресурсы представлены изданиями как на съемных носителях (компакт-диски), так и сетевыми. При наличии печатной и электронной версии в указатель включены сведения об обеих формах существования документа. В настоящее время он содержит около 2,6 тыс. библиографических записей.

Цель настоящего исследования - анализ библиографической продукции, изданной (в печатном и электронном виде) национальными библиотеками в 2010-2014 гг., сравнение нынешнего периода с предыдущим $-2004-2009$ гг. ${ }^{2}$, выявление тенденций развития.

Возросло общее количество изданий, подготовленных всеми национальными библиотеками: в среднем в год в 2004-2009 гг. издавалось 197 названий, в 2010-2014 гг. - 307. Такое увеличение объясняется не только активизацией издательской деятельности национальных библиотек, но и присоединением к проекту Президентской библиотеки им. Б.Н. Ельцина и Национальной библиотеки Армении. На общем фоне роста количества изданий, подготовленных национальными библиотеками, следует отметить и увеличение доли библиографических ресурсов: с $37,5 \%$ до $51 \%$. В абсолютных среднегодовых цифрах увеличение произошло в два раза: с 74 до 157 названий (см. Рис. 1).

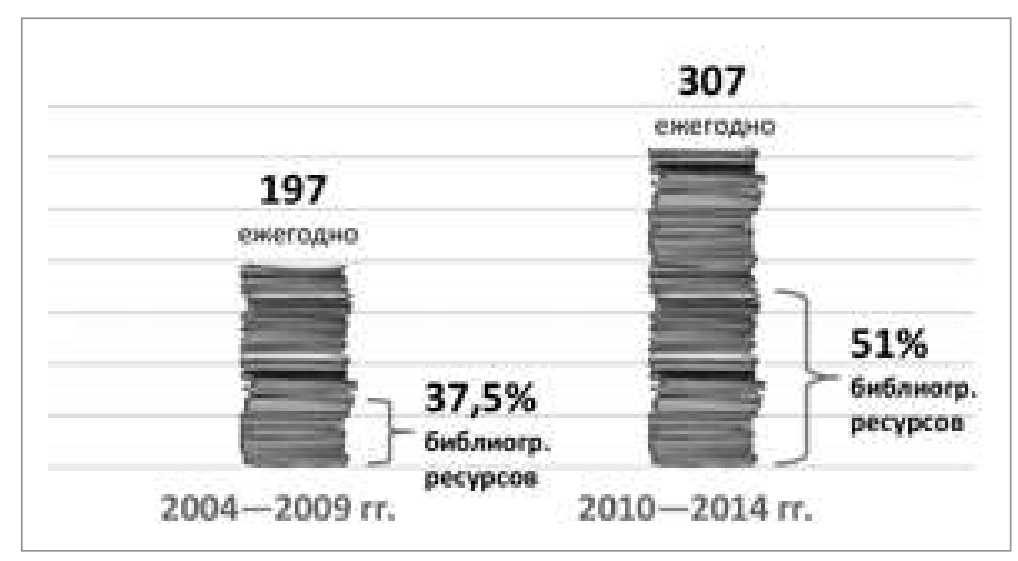

Рис. 1. Издания и электронные ресурсы нащиональных библиотек государств - участников СНГ

В одних библиотеках наблюдается значительный рост издаваемых ресурсов, например, в Национальной библиотеке Украины им. В.И. Вернадского в шесть раз, в Азербайджанской национальной библиотеке им. М.Ф. Ахундова - в 2,5 раза, в Российской национальной библиотеке - почти в два раза; в других библиотеках - цифры 


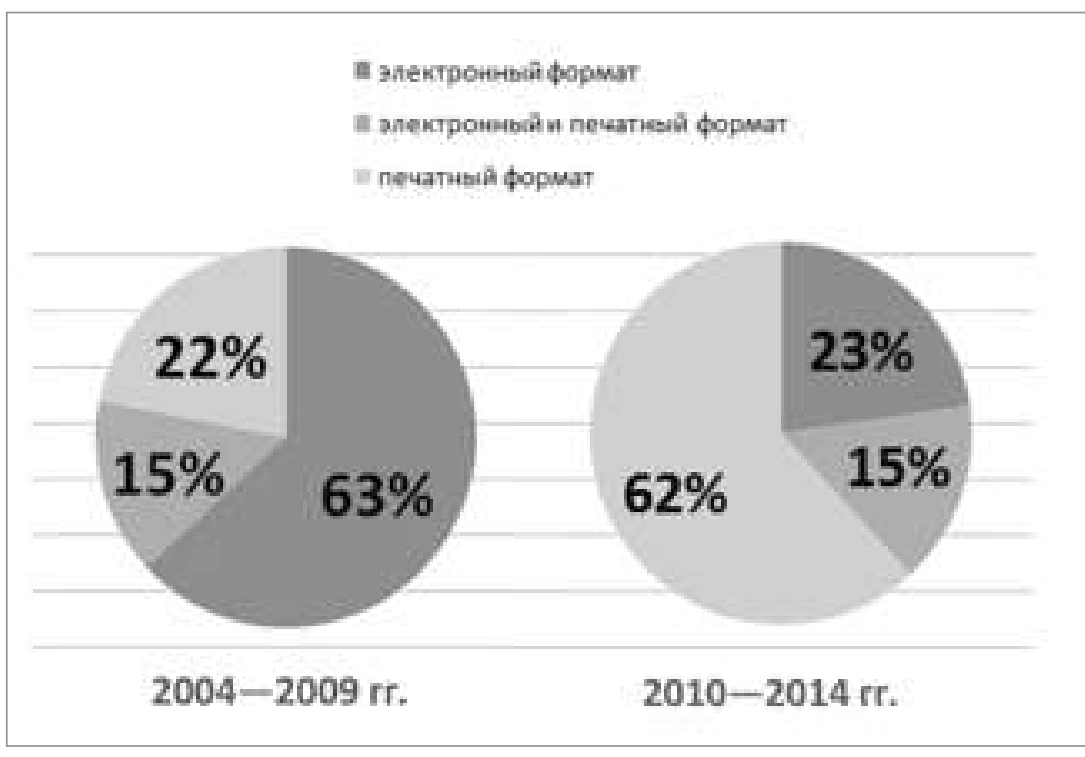

Рис. 2. Библиографические ресурсы национальных библиотек государств - участников СНГ

не изменились; а в третьих наблюдается спад, например, в Национальной библиотеке Республики Таджикистан в четыре раза уменьшилось количество издаваемых библиографических ресурсов. Одна из причин роста библиографических ресурсов (наряду с увеличением количества участников проекта) - увеличение количества виртуальных выставок, организуемых библиотеками, и создание на их основе электронных каталогов выставок: Национальная библиотека Украины им. В.И. Вернадского - 20 каталогов выставок в год, Российская государственная библиотека -5 , Российская национальная библиотека - 3.

Рассмотрим библиографическую продукцию национальных библиотек с точки зрения формата ее представления (см. Рис. 2).

Если в 2004 2009 гг. только в электронном формате распространялось $23 \%$ библиографических ресурсов, только в печатном $-62 \%$ и $15 \%$ были реализованы в двух форматах одновременно: печатном и электронном (в Интернет выставлялись оригинал-макеты печатных изданий), то сейчас - соответственно 63 в электронном, 22 в печатном и $15 \%$ одновременно в двух форматах. Лидером по созданию библиографической продукции в электронном виде является Прези- дентская библиотека им. Б.Н. Ельцина. Она всю библиографическую продукцию создает только в сетевом интернет-формате. В Национальной библиотеке Беларуси доля электронных библиографических ресурсов увеличилась с $68 \%$ до $90,5 \%$. Если в 2004-2009 гг. в Беларуси в Интернет было выставлено только одно библиографическое пособие (6\%), то сейчас шесть (32\%), остальные продолжают выходить на компакт-дисках. В целом наблюдается тенденция прекращения выпуска библиографических изданий на компакт-дисках. Например, РГБ с 2014 г. вообще прекратила выпускать библиографические ресурсы на компакт-дисках.

Если в предыдущий период три библиотеки - Азербайджана, Молдовы и Таджикистана - наиболее активно предоставляли интернет-сообществу оригинал-макеты печатных библиографических ресурсов, то теперь в тройке лидеров произошла замена: место Таджикистана заняла Национальная парламентская библиотека Украины.

Доля печатной библиографической продукции по сравнению с предыдущим периодом сократилась в два раза. Только в печатном виде представляют библиографические ресурсы национальные библиотеки Армении и Таджикистана.

Рассмотрим виды библиографической продукции национальных библиотек по назначению: общие библиографические ресурсы; специальные библиографические ресурсы; метабиблиография (см. Приложение).

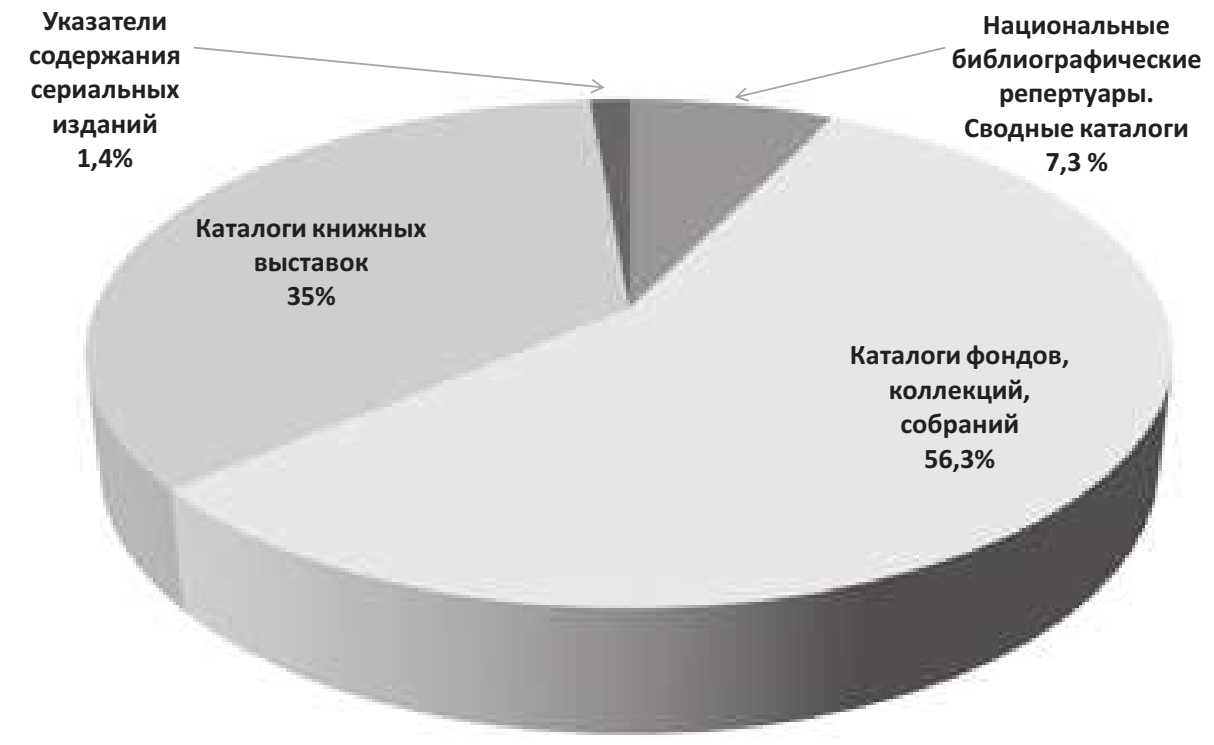

Всего 496 названий - 63\% от общего числа библиографических ресурсов 
За прошедший период библиотеки разрабатывали следующие виды общих библиографических ресурсов: национальные библиографические репертуары; сводные каталоги; каталоги фондов, коллекций и собраний; каталоги книжных выставок; указатели содержания сериальных изданий (см. Рис. 3).

За 2010-2014 гг. было создано 496 общих библиографических ресурсов, что составляет $63 \%$ от всех подготовленных библиографических пособий и вдвое больше, чем в $2004-2009$ годах $(30 \%)$. Наибольший процент этих изданий приходится на Президентскую библиотеку им. Б.Н. Ельцина (100\%), НБУВ (93\%), НБ Республики Молдова (75\%), РНБ (56,4\%).

Национальная библиография - это основа существования всех остальных видов библиографии. Первоочередной задачей любого государства, стремящегося сохранить память нации, является организация национального библиографического учета и создание на его базе национальной библиографии. Доля национальных библиографических репертуаров и сводных каталогов в составе ОБР в данный учетный период составляет $7,3 \%$, что несколько меньше, чем в предыдущий период $(12 \%)$. Всего пять библиотек в отчетном периоде издали пособия этого вида библиографии (Азербайджан, Молдова, НБУВ, РГБ, РНБ). Но работа ведется по многим направлениям, просто не все проекты еще завершены и представлены читателям.

Апробированным средством раскрытия библиотечных фондов является каталог. Этот вид ОБР был создан библиотекарями многие тысячелетия назад и до сих пор не потерял своей значимости. Поэтому неудивительно, что 56,3\% ОБР приходится на каталоги фондов, коллекций, собраний. Абсолютным лидером является Президентская библиотека им. Б.Н. Ельцина - 137 названий за $2010-2014$ гг. $(95,8 \%)$. Среднее количество отражаемых в них ресурсов составляет не более 20-30 названий. Каталоги, подготовленные другими библиотеками, насчитывают сотни и тысячи библиографических записей. Поэтому нельзя анализировать деятельность библиотек исходя только из количества подготовленных ресурсов, надо рассматривать и их наполнение. Современные информационные технологии, продуманная политика ведения электронного каталога позволяют ПБ им. Б.Н. Ельцина раскрывать свои фонды по различным аспектам исторической тематики. Фонд ПБ состоит только из электронных копий документов, оригиналы которых хранятся в других библиотеках, архивах, музеях.

Практически все НБ в данный учетный период начинают создавать электронные коллекции, библиотеки, фонды которых отражаются в специальных каталогах. Эти коллекции формируются или на основе своих фондов, или совместно с другими библиотеками страны и других государств. Отбор документов осуществляется по видам изданий, по тематике. Национальные библиотеки принимают участие также и в проектах по формированию коллегиальных электронных библиотек. Например, с 2010 г. в рамках БАЕ ведется проект «Золотая коллекция Евразии", в котором задействовано семь национальных библиотек. НБ Беларуси и НБ Республики Казахстан принимают участие в международном проекте «Электронная библиотека манускриптов». Национальная электронная библиотека «Moldavica» НБ Молдовы входит в состав Европейской электронной библиотеки и т. д. Каталоги таких коллекций представлены на сайтах библиотек.

Наиболее трудоемким направлением является раскрытие частных коллекций, архивов, фондов рукописных и старопечатных книг. Создание таких каталогов требует от составителей наличия углубленного знания предмета, владения техникой текстологического анализа и многих прочих навыков и умений. Каталоги фондов частных коллекций и книжных собраний ученых, деятелей культуры, науки, народ- 
ного просвещения, библиофилов составляли НБ Беларуси, Молдовы, Киргизии, Украины, России.

Каталоги книжных выставок помогают сохранить информацию, собранную и представленную в рамках временной экспозиции. Подготовкой данного вида ОБР занимались восемь НБ - Беларуси, Молдовы, Узбекистана, Украины (две библиотеки), России (три библиотеки) - $35 \%$ от всех ОБР. В последние годы НБ отдают предпочтение созданию каталогов виртуальных выставок. На их долю в каталогах выставок приходится 56,3\% .

Раскрытие содержания сериальных изданий не является приоритетным направлением библиографической деятельности НБ $(1,4 \%$ от общего числа ОБР). Как и в предыдущем учетном периоде, лидером является Национальная парламентская библиотека Украины. Еще две библиотеки - Армении и Украины (НБУВ) - разрабатывали этот вид общей библиографии.

Как и в предыдущие годы, специальные библиографические ресурсы (кроме ПБ им. Б.Н. Ельцина) создают все национальные библиотеки. В целом доля специальных библиографических ресурсов в период с 2010 по 2014 г. уменьшилась по сравнению с предыдущим периодом с $65 \%$ до $34 \%$ (см. Рис. 4). Почти все библиотеки составляли специальные библиографические пособия как в пе-

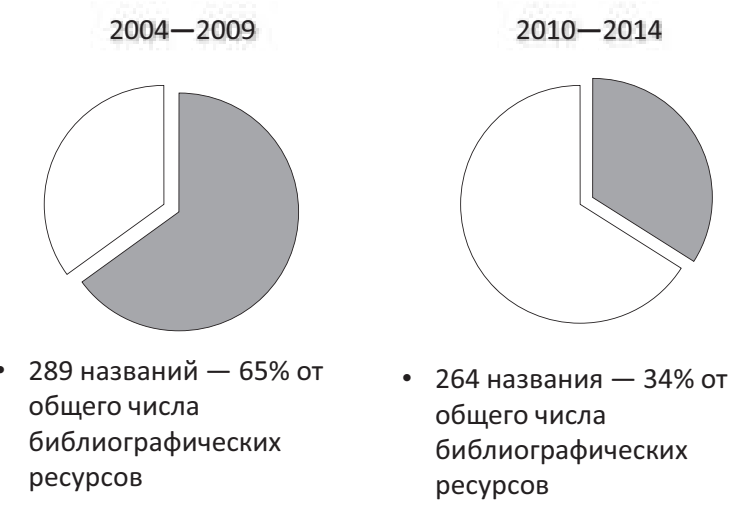

Рис. 4. Специальные библиографические ресурсы

чатном, так и в электронном виде. В специальной библиографической продукции нашли отражение материалы разнообразного содержания - тематические, отраслевые и биобиблиографические (монобиобиблиографические, полибиобиблиографические), адресованные разным категориям пользователей. Доля биобиблиографических пособий среди специальных ресурсов за 2010-2014 гг. составила $40 \%$.

Все национальные библиотеки, как и в предыдущие годы, уделяли особое внимание библиографическому обеспечению общественных и гуманитарных наук. Естественно-научные и технические науки остались охваченными в меньшей степени.

Практически все библиотеки составляли профессиональные указатели по библиотековедению

и библиографоведению. Это - списки изданий самих национальных библиотек, литературы о библиотеках, труды сотрудников, библиографические указатели материалов по различным вопросам теории, методики, истории библиотечного дела и библиографии, изданных в республиках.

На современном этапе развития информационных технологий перед специалистами всех отраслей науки и техники встает задача быстрого и оперативного поиска необходимой информации в электронном виде. Информационные технологии позволяют расширить возможности информационно-библиографического обслуживания. Однако ориентироваться в огромном и постоянно меняющемся массиве информационных электронных ресурсов значительно труднее, чем в традиционном печатном потоке. Поэтому одной из первоочередных задач становится создание полноценных путеводителей по Интернету. РНБ и РГБ создали ряд указателей, которые помогают пользователю отыскать такие подобные информационные ресурсы по различным отраслям знаний.

Библиографические указатели краеведческой, страноведческой тематики нашли отражение в издательской деятельности РНБ, национальных библиотек Азербайджана, Кыргызстана, Казахстана.

Важнейшим средством управления библиографической деятельностью являются Указатели библиографических ресурсов - метабиблиография. За учетный период не во всех библиотеках были созданы библиографические ресурсы данного вида. Разработкой направления «Библиография библиографии» или метабиблиографии как и в предыдущий период занимались только национальные библиотеки России и Украины (см. табл.).

таблица

\section{Указатели библиографических ресурсов (метабиблиография)}

\section{Библиотека}

Национальная библиотека Беларуси Национальная библиотека Украины им. В.И. Вернадского Национальная парламентская библиотека Украины

Российская государственная библиотека Российская национальная библиотека Итого

\begin{tabular}{|c|c|}
\hline $2004-2009$ гг. & 2010-2014 гг. \\
\hline 1 & - \\
\hline 3 & 1 \\
\hline 4 & 8 \\
\hline- & 3 \\
\hline 16 & 13 \\
\hline $24(5 \%)$ & $25(3 \%)$ \\
\hline
\end{tabular}

В процентном отношении к общему количеству созданных ресурсов этот вид библиографии немного снизился с 5\% до 3\% . Лидером осталась Российская национальная библиотека, на втором месте - Национальная парламентская библиоте- 
ка Украины. Библиография библиографии - направление, традиционно разрабатываемое в РНБ, что нашло отражение в ее задачах по созданию библиографической продукции и определило ее место среди других ресурсов - $11 \%$. Доля указателей библиографических ресурсов среди других источников, создаваемых Национальной парламентской библиотекой Украины, составляет $15 \%$. Обе библиотеки уделяют особое внимание формированию национального репертуара библиографических пособий.

В заключение можно констатировать, что наблюдается рост издательской продукции национальных библиотек, в частности, и за счет увеличения количества участников: было 12 , стало 14 . Если в 2004-2009 гг. библиотеки ежегодно в среднем издавали 197 названий, то в $2010-2014$ гг. -307 названий печатной и электронной продукции. Увеличилась и доля библиографической продукции с $37,5 \%$ до $51,3 \%$. В абсолютных среднегодовых цифрах увеличение произошло в два раза: с 74 до 157 названий. Все меньше библиографических ресурсов реализуется в печатном виде, а в электронном формате превалирует сетевой доступ (Интернет). Доля печатной библиографической продукции по сравнению с предыдущим периодом сократилась в два раза. Наблюдается тенденция прекращения выпуска библиографических изданий на компакт-дисках.

Существенные изменения произошли в выпуске общих и специальных библиографических ресурсов (см. Рис. 5).

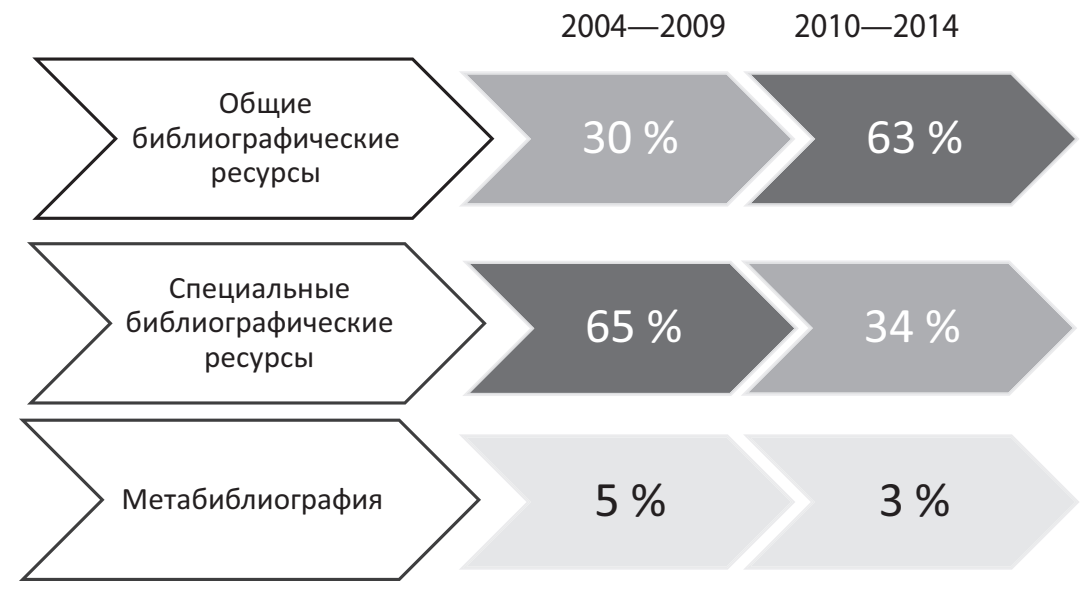

Рис. 5. Виды библиографических ресурсов

Если в 2004-2009 гг. на долю ОБР приходилось $30 \%$, то сейчас $63 \%$, соответственно доля специальных библиографических ресурсов снизилась с $65 \%$ до $34 \%$. Библиотеки сконцентрировали свое внимание и силы на создании общих библиографических ресурсов: в 2004-2009 гг. в год в среднем издавалось 22 ресурса, в $2010-$ 2014 гг. - 99. Это объясняется, в частности, и тем, что присоединившаяся к проекту Президентская библиотека им. Б.Н. Ельцина разрабатывает только это направление (все созданные ею 143 ресурса относятся к общей библиографии), а также увеличением издания каталогов выставок, в том числе и виртуальных: их доля в составе ОБР равняется $35 \%$. Доля национальных библиографических репертуаров и сводных каталогов в составе ОБР в 2010-2014 гг. снизилась до $7,3 \%$, в предыдущий период их было $12 \%$.

Небольшие изменения произошли в развитии метабиблиографии. Этот вид библиографии получил развитие только в библиотеках России и Украины. В абсолютных цифрах все осталось по-прежнему: $2004-2009$ гг. -24 названия, в 2010-2014 гг. -25 названий, но 
в процентном отношении наблюдается снижение с $5 \%$ до $3 \%$.

Появились примеры создания полнотекстовых баз данных на основе ранее изданных библиографических ресурсов.

Мы попытались создать объективную картину состояния издательской библиографической деятельности национальных библиотек, участвующих в данном проекте, и не можем сказать, кто лучше или хуже выполнял данную функцию. Каждая НБ внесла свой вклад в раскрытие библиотечных фондов и популяризацию интернетресурсов средствами библиографии. Библиотеки исходили из своих материальных возможностей, а также задач, которые стояли перед обществом, государством в данный исторический период, в целях удовлетворения информационных запросов потребителей как с помощью печатных источников, так и в режиме онлайн.

\section{Примечания}

1 Составители не имеют информации о деятельности Национальной библиотеки Республики Молдова в 2013-2014 годах.

2 Анализ деятельности национальных библиотек - членов БАЕ за 2004-2009 гг. см.: Теплицкая А.В., Жукова Л.В. Библиографическая продукция национальных библиотек - членов Библиотечной ассамблеи Евразии в XXI веке // Труды Международного библиографического конгресса : (Санкт-Петербург, 21-23 сент. 2010 г. / Рос. нац. б-ка. СПб., 2012. Ч. 1. С. 53-64.

Приложение

\section{Примеры библиографических ресурсов национальных библиотек - членов БАЕ}

\section{Национальные библиографические репертуары. Сводные каталоги}

- Свод русских книг кирилловской печати XVIII века типографий Москвы и Санкт- Петербурга и универсальная методика их идентификации / А.А. Гусева ; Рос. гос. б-ка. - Москва : Индрик, 2010.

- Обзоры губерний, областей и градоначальств Российской империи : (приложения к всеподданнейшим отчетам губернаторов, начальников областей и градоначальников), 1870-1916 : свод. кат. / А.И. Раздорский ; Рос. нац. б-ка, Рос. гос. ист. архив, Рос. гос. военно-ист. арх. Санкт-Петербург : Дмитрий Буланин, 2011.

- Национальная библиография Молдовы. Молдавистика (Экстериорика), 2010 / Нац. б-ка Респ. Молдова. - Кишинев : Нац. б-ка Респ. Молдова, 2012.
- Книга Азербайджана : библиография : в 10 т. Т. 3. (1941-1950) / Азерб. нац. б-ка им. М.Ф. Ахундова. - Баку, 2014.

- Книга на Украине, 1861-1917 : материалы к репертуару укр. кн. Вып. 18. «Ф, Х, Ц» / НАН Украины, Нац. б-ка Украины им. В.И. Вернадского. - Киев, 2014. - (Национальная библиография Украины).

- Международный сводный каталог русской книги (1918-1926). Т. 5. (Да - Дяо) / Рос. нац. б-ка. - Санкт-Петербург : РНБ, 2014.

\section{Каталоги фондов, коллекций, собраний}

- Нотные издания киргизских композиторов, поступившие в фонд ОКИ за годы независимости : библиогр. указ. / Нац. б-ка Кыргыз. Респ., Отд. культуры и искусства. - Бишкек, 2010.

- Каталог книг на персидском языке / Нац. б-ка Респ. Казахстан. - Алматы : ТОО «Полиграфкомбинат», 2011.

- Институт президентства в Российской Федерации. Законодательные акты [Электронный ресурс] : [коллекция] / Президент. б-ка им. Б.Н. Ельцина. - Санкт-Петербург : Президент. б-ка им. Б.Н. Ельцина, 2013.

- Наследие Юзефа Крашевского [Электронный ресурс] / Нац. б-ка Беларуси. - Минск : Нац. б-ка Беларуси, 2013.

- База данных редких изданий и рукописей [Электронный ресурс] : пополняемый, 2014 / Нац. б-ка Узбекистана им. Алишера Навои. - Ташкент : Нац. б-ка Узбекистана им. Алишера Навои, 2014.

- Газетный мир России XIX - начала $\mathrm{XX}$ века : кат. дореволюц. газет в фондах Рос. гос. б-ки : в 2 т. / Рос. гос. б-ка, Отд. газет. - 3-е изд. испр., доп. - Москва : Пашков дом, 2014.

\section{Каталоги книжных выставок}

- «Ради пользы и славы Отечества» : к 300-летию со дня рождения М.В. Ломоносова : кат. выст. / Рос. нац. б-ка. - Санкт-Петербург, 2011.

- Виктор Телеукэ. Попытка не умирать : кат. выст. / Нац. б-ка Респ. Молдова. - Кишинёв : НБРМ, 2012.

- К 200-летию со дня рождения великого украинского поэта и художника Т.Г. Шевченко [Электронный ресурс] : кн., представл. на выст. / Нац. б-ка Украины им. В.И. Вернадского. Киев, 2014.

- «Молитвенник земли Русской». К 700-летию со дня рождения преподобного Сергия Радонежского [Электронный ресурс] : список журн., представл. на выст. / Рос. гос. б-ка. - Москва, 2014. 


\section{Указатели содержания сериальных изданий}

- «Курьер Кривбасса» (2005-2009) : сист. указ. содерж. / М-во культуры и туризма Украины, Гос. учреждение «Нац. парлам. б-ка Украины». - Киев, 2010.

- «Общественное мнение» [газ. «Громадська думка»] : аннот.

II Международный библиографический конгресс сист. указ., 1905-1906 гг. / Нац. б-ка Украины им. В.И. Вернадского. - Киев : Темпера, 2011.

- Мшак [Тифлис, 1872-1921 гг. : газета] : библиогр. содерж., 1880 / Нац. б-ка Армении. - Ереван, 2014.

\section{Специальные библиографические ресурсы}

- Издания Национальной библиотеки Республики Казахстан (1931-2011) : в 2 ч. : библиогр. указ. / Нац. б-ка Респ. Казахстан. Алматы, 2011.

- Труды сотрудников Российской национальной библиотеки за 2006-2010 гг. : библиогр. указ. / Рос. нац. б-ка. - Санкт-Петербург : РНБ, 2013.

- Библиография. Библиографоведение : указ. лит., изд. в Рос. Федерации на рус. яз. в 2001-2010 гг. : [в 3 ч.] / Рос. гос. б-ка, Науч.-исслед. отд. библиогр. - Москва : Пашков дом, 2013 - 2014.

- Национальная библиотека Кыргызской Республики (19342014) : к 80-летию со дня образования : [библиография] / Нац. б-ка Кыргыз. Респ. - Бишкек, 2014.

- [Национальная библиотека Узбекистана им. Алишера Навои [Электронный ресурс] : [ст. сотрудников б-ки, опублик. в местн. и заруб. СМИ] / Нац. б-ка Узбекистана им. Алишера Навои. — Ташкент, 2014.

- Памятники Астаны : каталог-указатель [Электронный ресурс] / Нац. акад. б-ка Респ. Казахстан. - Астана, 2013.

- Путеводитель по справочным и библиографическим ресурсам. Петербурговедение [Электронный ресурс] / Рос. нац. б-ка. - СанктПетербург : РНБ, 2013.

- История России в Рунете [Электронный ресурс] / Рос. гос. б-ка, НИо библиографии. - Москва, 2014.

- Обзор психологических ресурсов Интернета [Электронный ресурс] / Рос. гос. б-ка, НИО библиогр. - Москва, 2014.

- Гении всех времен : указ. лит. из цикла «Классики таджикско-персидской литературы» : в 3 ч. / Нац. б-ка Таджикистана. Душанбе, 2014.

\section{Метабиблиография}

• Библиография русской библиографии, 1901-1916 [Электронный ресурс] / Рос. гос. б-ка, Науч.-исслед. отд. библиогр. - Москва, 2011.

- Пособия научной библиографии, изданные на Украине (1991$2005)$ : науч.-вспом. библиогр. указ. : в 2 ч. / М-во культуры Украины, Гос. учреждение «Нац. парлам. б-ка Украины». — Киев, 2011.

- Острой О.С. Изобразительное и прикладное искусство : указ. библиогр. пособий, 1789-2007 гг. / О.С. Острой, И.Х. Саксонова ; Рос. нац. б-ка. - Санкт-Петербург, 2012.

- Метабиблиография Украины (2011) : библиогр. указ. / М-во культуры и туризма Украины, Гос. учреждение «Нац. парлам. б-ка Украины». - Киев, 2012.

Контактные данные: 119019, Москва, ул. Воздвиженка, Ә. 3/5; e-mail:TeplitskayaAV@rsl.ru 